\title{
MOTIVOS DE CONSULTA FRECUENTES Y SU MANEJO
}

\section{Mastalgia}

Este síntoma es muy común en mujeres en edad reproductiva, y es motivo de consulta bastante frecuente. En una proporción importante de los casos la preocupación de la paciente no es tanto el dolor en sí, sino la posibilidad de que este síntoma represente una entidad grave como el cáncer. Hay que recordar que éste raramente causa mastalgia (por lo menos en sus fases iniciales); sin embargo la valoración debe dirigirse a descartar esta entidad. Sólo el $6 \%$ de los cánceres mamarios presentan dolor.

En primera instancia se interrogará si el síntoma es cíclico; si lo es, podemos estar bastante confiados de que estamos frente a un proceso físiológico por cambios hormonales, especialmente en pacientes jóvenes con estados hiperestrogénicos. Su intensidad puede ocasionar incapacidad laboral. La mastalgia acíclica se presenta más en estados avanzados de condición fibroquística y no está asociada en general con trastornos hormonales.

Se debe realizar a continuación un examen físico detallado y completo para descartar la presencia de masas. En caso de encontrarlas, serán enfocadas como se mencionará más adelante. En mujeres de más de 35 años se realizará una mamografía, especialmente si el dolor es continuo. No debemos olvidar descartar aquellas causas de dolor de origen extramamario.
En la mayoría de los casos, el asegurar a la paciente que el estudio ha descartado patología maligna constituye el único tratamiento necesario. Igualmente hay que darle la confianza de que su síntoma no aumenta el riesgo de sufrir cáncer de mama (dicho riesgo se asocia a la histología de ciertas lesiones, no con la mastalgia en sí). También se le debe recordar que su síntoma es usualmente autolimitado y que se resolverá espontáneamente en pocos meses.

\section{Tratamiento}

Se puede recomendar el uso de un sostén apretado para disminuir el roce y movimiento. Durante los períodos de exacerbación del dolor están indicados los analgésicos no opioides, los AINES y medidas locales físicas a base de calor o frío. Se deberá hacer seguimiento al cabo de 2 ó 3 meses para asegurarnos de que no ha habido cambios (especialmente la aparición de masas) y evaluar la respuesta al manejo expectante.

Para aquellos raros casos que no responden a este manejo, y si el dolor es muy severo, se podrá iniciar terapia farmacológica cuyo objetivo es disminuír la influencia de los estrógenos sobre la glándula. Antes de tomar este paso se deben sopesar cuidadosamente los efectos secundarios que tienen los fármacos utilizados con sus posibles beneficios. Los agentes más utilizados son:

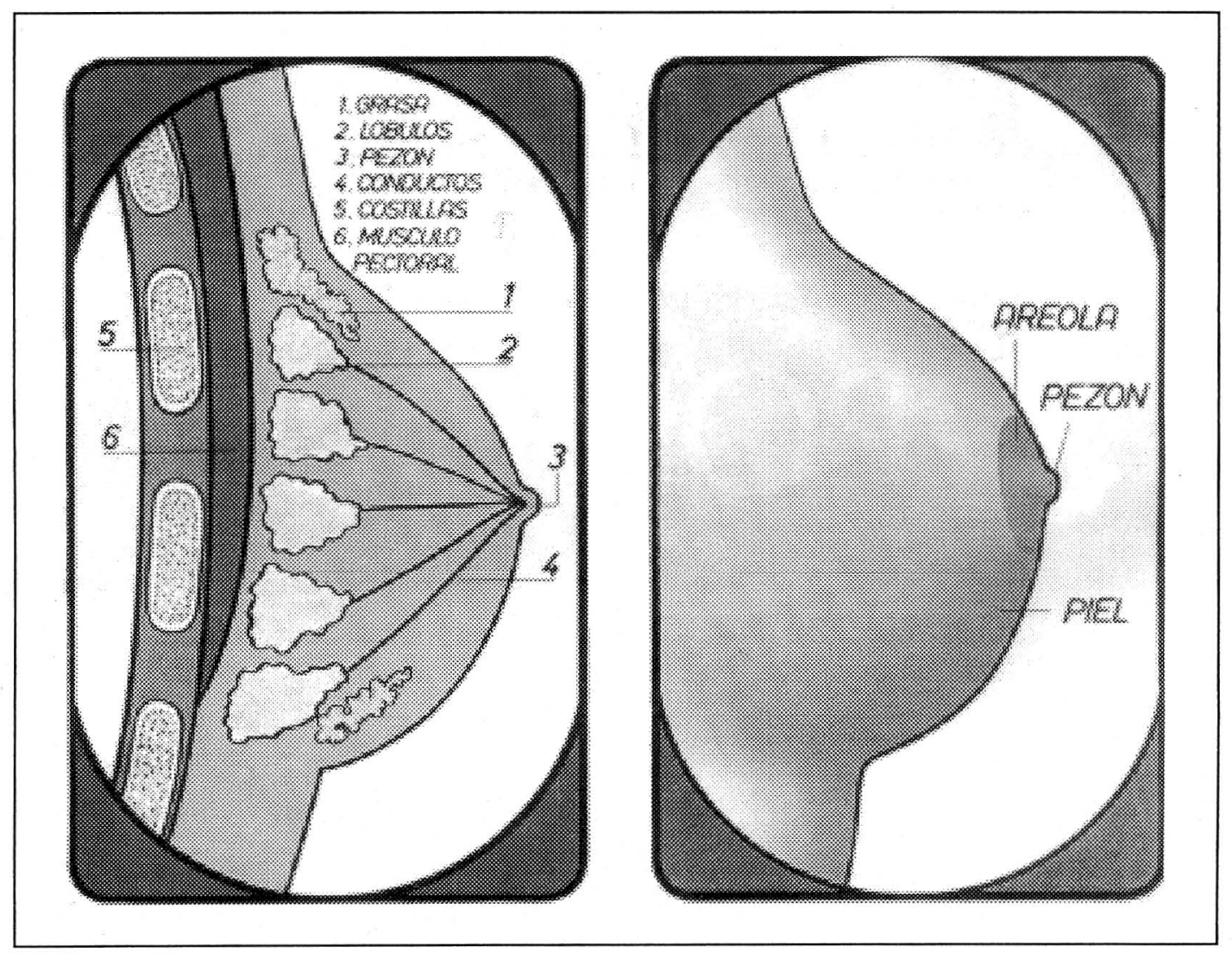


Progestágenos: La medroxiprogesterona en dosis de 5 a $10 \mathrm{mg}$ durante los días 16 a 25 del cicloha sido utilizada con resultados controvertidos, ya que recientemente se ha demostrado que no existe un estado de hipoprogesteronismo relativo durante el ciclo menstrual. También se reconoce el efecto proliferativo de la progesterona sobre las células alveolares de los lóbulos mamarios (que es un contrario al efecto observado en el endometrio) y que podría agravar el cuadro.

Danazol: con dosis de 50 a $400 \mathrm{mg} /$ día se puede obtener alivio, pero con el inconveniente de sus efectos colaterales de aumento de peso, acné, androgenización, etc.

Tamoxifén: a dosis de $10 \mathrm{mg}$ del día 5 a 25 , con resultados menos alentadores y con efectos colaterales como bochornos, náuseas y mareos.

Bromocriptina: en dosis de 5 a $7.5 \mathrm{mg}$. es otra posibilidad terapéutica, especialmente en pacientes hiperprolactinémicas. Tiene la desventaja de su mala tolerancia.

Dieta y Vitaminas: el manejo dietético evitando las metilxantinas, que tiene la ventaja de su inocuidad, no ha demostrado clara utilidad. Igual puede decirse del tratamiento con vitaminas B y E. Una dieta baja en grasas puede ser beneficiosa.

Cualquier tipo de abordaje farmacológico que se haga deberá continuarse por un mínimo de tres meses para evaluar la respuesta, y los tratamientos hormonales por períodos de seis meses.

\section{Mastalgia de Origen Extramamario}

Cualquier dolor en la cara anterior del tórax puede ser interpretado por la paciente como de origen mamario ante su temor al cáncer de mama. Muchas veces es producido por un sinnúmero de entidades diferentes extrínsecas a la mama, como: acalasia, radiculitis cervical, costilla cervical, colelitiasis, coronariopatía, costocondritis (Tietze), hernia hiatal, mialgia, neuralgia, dolor fantasma, pleuresía, dolor psicológico, traumático, $\mathrm{TBC}$, etc.

La compresión firme de la mama puede reproducir el dolor. El dolor sin tumor palpable rara vez constituye el único síntoma de presentación del cáncer de mama; cuando éste es avanzado puede ser doloroso pero también es obvio clínicamente.

\section{Engrosamiento Mal Definido o Nodularidad}

La textura del tejido mamario normal es heterogénea, particularmente en la mujer premenopáusica. Esa variación normal de la textura del parénquima crea áreas que se sienten más firmes y en ocasiones nodulares, y que pueden o no ser sensibles a la palpación. Estos engrosamientos difusos y las áreas de nodularidad son bastante frecuentes y deben ser distinguidos de una masa verdadera.

En la práctica clínica estos hallazgos deben someterse a comparación con el área correspondiente del seno contralateral, buscando simetría. Los hallazgos simétricos raramente son patológicos. Las áreas de engrosamiento o nodularidad asimétrica en mujeres premenopáusicas, particularmente si son sensibles a la palpación, representan en un alto porcentaje de casos condición fibroquística y se resuelven espontáneamente.
Si la paciente es mayor de 35 años se practicará una mamografía (en pacientes menores la conveniencia de realizar este examen debe individualizarse de acuerdo al riesgo). La ecografía mamaria en menores de 35 anos está justificada ante duda clínica. Al cabo de dos o tres ciclos menstruales se realizará un nuevo examen físico en los primeros días del ciclo. Si hay persistencia de la asimetría, la paciente deberá ser evaluada por un profesional entrenado quien definirá la conveniencia de realizar biopsia.

\section{Secreción por el Pezón - Telorrea -}

Produce gran ansiedad a la paciente y preocupación al médico. Se describen varios tipos:

-Lechosa,multicolorida y purulenta: generalmente producida por procesos benignos. El tratamiento es médico y es fundamental tranquilizar a la paciente.

- Clara o acuosa, serosa, rosada y sanguinolenta: pueden ser producto de cáncer por lo cual pueden requerir estudio histológico, citología de la secreción y bacaf si se palpa masa. Es importante conocer y anotar si la secreción es unilateral o bilateral, espontánea o provocada, recurrente o continua y su relación con el ciclo menstrual.

-Provocada: entre 60 y 70\% de las mujeres normales tendrán secreción al exprimirse los pezones; ésta es amarilla o verdosa y no guarda relación con procesos patológicos. Debe distinguirse de la secreción espontánea, la cual sí requiere de estudio.

-Galactorrea: Se le denomina así cuando es bilateral, por múltiples ductos, y de aspecto lácteo; casi nunca está asociada a patología mamaria maligna, y guarda más bien relación con alteraciones endocrinas o ingesta de medicamentos. Descartada esta posibilidad, se debe practicar una cuantificación de prolactina y estudios de función tiroidea. Si se encuentran valores de de prolactina mayores de 100 y alteraciones del ciclo menstrual, está indicado el TAC de silla turca para excluir la presencia de un adenoma hipofisiario. Descartado éste, se procede al tratamiento específico con dopaminérgicos. De otro lado, si se documenta un hipotiroidismo, se hará el tratamiento específico.

La descarga unilateral o sanguinolenta, acuosa o de color café debe ser estudiada más a fondo por una persona entrenada. Se debe tratar de definir el cuadrante y/o el ducto de donde proviene la secreción, y si hay masa asociada. En las pacientes de más de 35 años se practicará mamografía. La resección de conductos terminales es el procedimiento de elección para descartar malignidad y como medida terapéutica. Si hay masa asociada, se debe practicar biopsia de ésta.

Las secreciones asociadas a patología del conducto terminal, benignas o malignas tienen las siguientes características: espontáneas, persistentes, unilaterales, sanguinolentas, acuosas y/o sero sanguinolentas.

\section{Otras Patologías de Pezón y Areola}

La erosión y lesiones eczematosas del pezón deben hacer sospechar la posibilidad de enfermedad de Paget del pezón, que generalmente se asocia a carcinoma infiltrante, 
aunque en algunas oportunidades corresponde a un carcinoma intraductal originado en el epitelio de los conductos terminales. Se requiere la biopsia por el especialista para hacer un diagnóstico definitivo y orientar el tratamiento. Usualmente se presenta en mayores de 35 años.

\section{Patología Infecciosa}

Las infecciones de la mama se dividen en tres grandes categorías:

1 Las asociadas con la lactancia (mastitis puerperales).

2. Las infecciones subareolares crónicas asociadas con ectasia ductal.

3. Otros abscesos no relacionados con la lactancia.

Las mastitis puerperales se tratan en sus fases iniciales (si no hay absceso aún), con antibióticos que cubran cocos gram positivos, compresas tibias y vaciamiento frecuente de la mama. No es necesario en este punto suspender la lactancia. Una vez formado un absceso,es necesaria la suspensión de la lactancia y el drenaje abierto bajo anestesia general.

Mastitis periductal o ectasia ductal: los ductos subareolares desarrollan en ocasiones un tipo de infección crónica recurrente en mujeres no lactantes. Su manifestación son los abscesos periareolares a repetición, retracción o inversión del pezón y en ocasiones fístulas de los conductos subareolares a la piel periareolar. Los gérmenes más frecuentemente implicados son mixtos, e incluyen flora anaeróbica y gram-negativa de piel. El tratamiento en la fase aguda debe incluir antibioticoterapia dirigida a dichos gérmenes y drenaje. Las fístulas deben ser tratadas con antibioticoterapia y resección de los conductos comprometidos o del complejo ductal subareolar en su totalidad. Uno de los diagnósticos diferenciales lo constituye la Mastitis Granulomatosa Crónica, caracterizada también por mastitis a repetición,fístulas periareolares únicas o múltiples, uni o bilaterales. Se debe confirmar debe por patología y tratarse con tuberculostáticos a base de Rifampicina e Isoniazida. Descartada la etiología infecciosa, cabría la posibilidad de tratamiento con corticoides $10 \mathrm{mgrs} /$ día por 3 meses.

Otros abscesos:Pueden ocurrir igualmente abscesos en la periferia del tejido mamario en pacientes que no están lactando. Sin embargo el tratamiento será similar al de aquellas. Se debe recordar que su ocurrencia es rara, y que se debe tener presente la posibilidad de malignidad.

\section{Masa Palpable}

Las masas discretas, o sea aquellas que claramente se diferencian del tejido mamario circundante sin alcanzar dimensiones importantes, pueden ser sólidas o quísticas. Distinguir entre estas dos posibilidades es muy importante, ya que esto es lo que definirá el manejo. El enfoque se realizará de acuerdo con los factores de riesgo que se detallan en la siguiente sección, y con los hallazgos clínicos y paraclínicos que se mencionan en la parte de valoración diagnóstica, donde también se discutirá su abordaje. 